each coping-skills module. Copingskills training should be used with groups of schizophrenic patients in other settings. In addition to goal attainment, the impact of copingskills training on symptomatology and domains of functioning should be assessed.

Results of this study suggest the usefulness of cognitive interventions with schizophrenic patients. Coping-skills training provides a potentially valuable means to enhance schizophrenic patients' ability to cope with stress and provides a promising approach that can augment traditional treatment of schizophrenia.

References

1. Anthony W, Cohen M, Vitalo R: The measurement of rehabilitation outcome. Schizophrenia Bulletin 4:365-383, 1978

2. Zukoff D, Snyder K, Ventura J, et al: Life events, familial stress, and coping in the developmental course of schizophrenia. Schizophrenia Bulletin 10:258292, 1984

3. Zubin J: Possible implications of the vulnerability hypothesis for the psychosocial management of schizophrenia, in Psychosocial Management of Schizophrenia. Edited by Strauss J. Toronto, Huber, 1986

4. Tallant S, Rose S, Tolman R: New evidence for the effectiveness of stress management training in groups. Behavior Modification 13:431-446, 1989

5. Subramanian K: Structured group work for the management of chronic pain. Research on Social Work Practice 1:32-46, 1991

6. Tolman R, Rose S: Coping with stress: a multimodal approach. Social Work 3: 151-158, 1985

7. D'Zurilla T, Goldfried M: Problem solving and behavior modification. Journal of Abnormal Psychology 78:107-126, 1971

8. Wallace $C$, Boone S: Cognitive factors in the social skills of schizophrenic patients. Nebraska Symposium on Motivation 31 : 283-318, 1990

9. Kiresuk TS, Sherman RE: Goal Attainment Scaling: a general method for evaluating comprehensive community mental health programs. Community Mental Health Journal 4:443-453, 1968

10. Beidel D, Turner S, Bellack A, et al: Using the Goal Attainment Scale to measure treatment outcome in schizophrenia. International Journal of Partial Hospitalization 2:33-41, 1982

\title{
HIV Risk Activity Among Persons With Severe Mental Illness: Preliminary Findings
}

\author{
Francine Cournos, M.D. \\ Karen McKinnon, M.A. \\ Heino Meyer-Bahlburg, Dr. \\ Rer. Nat. \\ Jeannine R. Guido, M.A. \\ Ilan Meyer, M.A., M.Phil.
}

HIV seroprevalence rates between 5.5 percent and 8.9 percent have been reported among hospitalized psychiatric patients in New York City $(1,2)$. The prevalence of two key HIV-risk activities in this population, unsafe sex and drug injection, has not been adequately investigated.

At two public psychiatric hospitals, charted histories of homosexual activity were found for 18 of 237 men ( 7.6 percent), and drug injection was documented for 39 of 451 men and women (8.6 percent) (1). Using written questionnaires, one study found that nearly half of 113 acutely hospitalized psychiatric patients reported a history of HIV-related risk behaviors during the previous five years (3). In another study at an inner-city outpatient psychiatric clinic, more than half of 60 patients had engaged in risk behaviors in the past year (4). Most risk behaviors were related to unsafe sexual activities. Rates of injection-drug use during the period under investigation were 5 percent in both studies $(3,4)$.

Psychiatric diagnoses may affect risk behavior. Patients with bipolar disorder have been observed to experience periodic hypersexuality (2). Chronic psychopathology among pa-

The authors are affiliated with the New York State Psychiatric Institute, 722 West 168th Street, New York, New York 10032, and the department of psychiatry at the College of Physicians and Surgeons of Columbia University. tients with schizophrenia may decrease the frequency of sexual activity (5) and use of narcotics (6).

The objective of the study reported here was to assess risk behaviors associated with HIV infection among severely mentally ill persons using carefully established research diagnoses and lengthy face-to-face interviews about risk behaviors.

\section{Methods}

All patients between the ages of 18 and 59 who were judged by the treating clinician to be capable of consenting to research were approached at three sites that provide services to severely and persistently mentally ill persons. Of the 264 patients approached, 200 agreed to participate, an acceptance rate of 76 percent. This paper reports findings for the first 95 patients who completed interviews.

Study sites were a day treatment program, an acute inpatient unit, and a state hospital unit that prepares patients for community living. At all sites it was the policy to exclude from treatment persons with primary diagnoses of substance use disorders. Participants had recent opportunities for sexual activity and drug use off hospital grounds.

Each consenting patient underwent a structured set of face-to-face interviews. Each assessment consisted of the Structured Clinical Interview for DSM-III-R (7); an adaptation of the Parenteral Drug Use High-Risk Questionnaire (8), which is an interview about use of injection drugs, and the Sexual Risk Behavior Assessment Schedule, which elicits detailed information about behaviors in the preceding six months and some information about lifetime sexual history (9). The sexual interview was designed to put patients at ease when talking about sex and con- 
Table 1

HIV risk behaviors among 95 patients with severe mental illness, by diagnostic group

\begin{tabular}{|c|c|c|c|c|c|c|c|c|}
\hline \multirow[b]{2}{*}{ Risk behavior } & \multicolumn{2}{|c|}{$\begin{array}{l}\text { Schizo- } \\
\text { phrenia } \\
(\mathrm{N}=47)\end{array}$} & \multicolumn{2}{|c|}{$\begin{array}{l}\text { Bipolar } \\
\text { disorder } \\
(\mathrm{N}=17)\end{array}$} & \multicolumn{2}{|c|}{$\begin{array}{l}\text { Other } \\
(\mathrm{N}=31)\end{array}$} & \multicolumn{2}{|c|}{$\begin{array}{l}\text { Total } \\
(\mathrm{N}=95)\end{array}$} \\
\hline & $\mathbf{N}$ & $\%$ & $\mathbf{N}$ & $\%$ & $\mathbf{N}$ & $\%$ & $\mathbf{N}$ & $\%$ \\
\hline \multicolumn{9}{|l|}{ Homosexual activity } \\
\hline Past six months & 2 & 4.3 & 0 & - & 0 & - & 2 & 2.1 \\
\hline Lifetime & 10 & 21.3 & 2 & 11.8 & 5 & 16.1 & 17 & 17.9 \\
\hline \multicolumn{9}{|l|}{ Drug injection } \\
\hline Past six months & 0 & - & 0 & - & 1 & 3.2 & 1 & 1.1 \\
\hline Since 1978 & 9 & 19.1 & 4 & 23.5 & 6 & 19.4 & 19 & 20.0 \\
\hline \multicolumn{9}{|l|}{$\begin{array}{l}\text { Heterosexual activity, } \\
\text { past six months }\end{array}$} \\
\hline Abstinent & 22 & 46.8 & 6 & 35.3 & 12 & 38.7 & 40 & 42.1 \\
\hline One partner & 10 & 21.3 & 5 & 29.4 & 11 & 35.5 & 26 & 27.4 \\
\hline Multiple partners & 15 & 31.9 & 6 & 35.3 & 8 & 25.8 & 29 & 30.5 \\
\hline \multicolumn{9}{|l|}{$\begin{array}{l}\text { Condom use, past six } \\
\text { months }\end{array}$} \\
\hline \multicolumn{9}{|c|}{$\begin{array}{l}\text { Among subjects reporting } \\
\text { one sexual partner }\end{array}$} \\
\hline No condom use & 5 & 62.5 & 3 & 60.0 & 9 & 90.0 & 17 & 74.0 \\
\hline Inconsistent use & 1 & 12.5 & 1 & 20.0 & 1 & 10.0 & 3 & 13.5 \\
\hline Consistent use & 2 & 25.0 & 1 & 20.0 & 0 & - & 3 & 13.5 \\
\hline \multicolumn{9}{|c|}{$\begin{array}{l}\text { Among subjects reporting } \\
\text { multiple sexual partners }\end{array}$} \\
\hline No condom use & 6 & 40.0 & 2 & 40.0 & 3 & 37.5 & 11 & 39.3 \\
\hline Inconsistent use & 8 & 53.3 & 2 & 40.0 & 5 & 62.5 & 15 & 53.6 \\
\hline Consistent use & 1 & 6.7 & 1 & 20.0 & 0 & - & 2 & 7.1 \\
\hline
\end{tabular}

${ }^{1}$ Diagnoses include schizoaffective disorder, major depressive disorder, psychotic disorder not otherwise specified, and atypical psychosis.

${ }^{2}$ Condom use data were missing for some patients.

tained techniques for improving accuracy of recall. The reliability of selected variables from this instrument has been demonstrated with psychiatric patients (10). Chi square analyses were used to test differences between groups.

\section{Results}

Sample characteristics. Of the 95 participants, 53 ( 55.8 percent) were from the community preparation unit, 27 (28.4 percent) from the day treatment unit, and 15 (15.8 percent) from the acute care unit. Demographically and clinically, participants reflected the census in these settings.

The mean $\pm \mathrm{SD}$ age of patients was $35.4 \pm 8.4$ years. The mean number of previous psychiatric hospitalizations

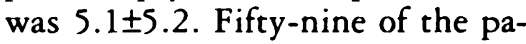
tients ( 62 percent) were men. A total of 43 patients ( 45.3 percent) were black, 26 (27.4 percent) were Hispa- nic, and 26 were either white or from other ethnic groups.

Risk factors. No significant differences in sexual activity were found between patients at the three sites, including being abstinent, having more than one partner in the previous six months, or using condoms. Nor were differences in injectiondrug use found. Therefore, patient data from the three sites were combined for subsequent analyses.

Table 1 shows risk characteristics of the 95 participants by diagnostic group: schizophrenia, bipolar disorder, and other diagnoses (schizoaffective disorder, major depressive disorder, psychotic disorder not otherwise specified, and atypical psychosis). No significant differences between the diagnostic groups were found in the rate of abstinence, number of sexual partners, condom use, homosexual behavior, or drug injection.

Recent sexual activity. Overall,
55 patients ( 57.8 percent) reported engaging in sexual activity during the past six months. Thirty-two of 59 male patients ( 54.2 percent) and 23 of 36 female patients (63.9 percent) reported recent sexual activity. No significant differences between men and women were found in the rate of abstinence, number of partners, or condom use during vaginal or anal intercourse.

Age, gender, and ethnicity were not significantly associated with being sexually active. However, sexually active patients under age $\mathbf{4 0}$ were significantly more likely to have multiple partners than those over age 40. In the younger group, 15 patients ( 37.5 percent) had one sexual partner, and 25 (62.5 percent) had multiple partners. Among patients age 40 or older, 11 ( 73.3 percent) had one sexual partner, and four (26.7 percent) had multiple partners $\left(\chi^{2}=4.27, \mathrm{df}=1, \mathrm{p}=.04\right.$, Yates' continuity correction).

Condom use during heterosexual vaginal and anal intercourse was analyzed for 51 patients for whom complete information was available. Only five patients (9.8 percent) reported using condoms for each act of intercourse. Twenty-eight patients ( 54.9 percent) never used condoms. The remaining 18 patients $(35.3$ percent) used condoms inconsistently. Condom use did not vary significantly by age, gender, or ethnic group. Patients with multiple partners were more likely to use condoms than those who were monogamous. Eleven of 28 patients ( 39.3 percent) who never used condoms reported having multiple partners, while 17 of 23 patients ( 73.9 percent) who used condoms, albeit inconsistently, had multiple partners $\left(\chi^{2}=6.11\right.$, $\mathrm{df}=1, \mathrm{p}=.01$ ).

Heterosexual anal intercourse was reported by seven of 31 men $(22.6$ percent) and five of 23 women (21.7 percent). None of the men and two of the women used condoms.

Homosexual history. Only two (3.6 percent) of the 55 sexually active patients (one man and one woman) reported current homosexual activity. These two patients also reported heterosexual activity during the past six months. No patient reported ho- 
mosexual activity exclusively or homosexual anal intercourse.

Seventeen (18.5 percent) of the 92 patients for whom complete information was available reported homosexual behavior at some time in the past; 11 of 58 men ( 19 percent) and six of 34 women (17.6 percent) reported such past behavior. Ten of the patients were currently sexually active, but only one reported current homosexual behavior.

Drug injection. Of the $95 \mathrm{pa}-$ tients, only one reported drug injection in the previous six months, sharing injection equipment once during that time. Drug injection at least once since 1978 was reported by 19 patients ( 20 percent) -13 men (22 percent) and six women (16.7 percent). No significant association was found between drug injection and age, gender, ethnicity, or psychiatric diagnosis.

Discussion and conclusions This study of HIV risk behaviors among severely mentally ill patients yielded some surprising findings. First, rates of sexual activity and drug injection were not related to diagnosis. Despite previous reports suggesting that differences might be found, bipolar disorder was not associated with a greater likelihood of sexual activity, nor schizophrenia with abstinence or lower rates of drug injection.

Second, unsafe heterosexual activity was by far the most common current risk behavior, rather than the classical risk factors of male homosexual activity and drug injection. However, past participation in both homosexual activity and drug injection were more impressive than current participation in these activities might suggest, and, despite the treatment sites' exclusion of individuals with a primary diagnosis of a substance use disorder, a surprising 20 percent of all patients had injected drugs at least once since 1978.

A third unexpected finding was that younger age did not predict sexual activity, although younger patients were more likely to have multiple partners. Only 9.8 percent of sexually active patients consistently used condoms.

The patients in our study had an average of five previous psychiatric hospitalizations. These findings may not be applicable to patients who are more acutely ill or who have milder illnesses. Nor may they be applicable to patients outside of urban settings. An additional limitation is the lack of information about patients not referred to this research project because they were deemed unable to give consent. Although our patients appeared to be comfortable answering very explicit sexual questions, we cannot exclude the possibility that the low rates of current homosexual activity represented underreporting.

In conclusion, unprotected heterosexual intercourse was the most frequent current HIV risk activity in this group of patients with chronic mental illness. However, past use of injection drugs and homosexual activity were important factors in the sample. Although these behaviors were less frequent, they may represent more serious risk factors because HIV may be more easily transmitted by these routes. In our experience, patients are willing and able to discuss HIV risk behaviors, which should permit the development and implementation of appropriately targeted risk reduction interventions.

\section{Acknowledgments}

This study was supported by grant $\mathrm{MH}$ 46251 from the National Institute of Mental Health and by the New York State Office of Mental Health. The authors thank Louis Caraballo, Diane Engel, M.S.W., Elizabeth Margoshes, Ph.D., Brenda Agosin, M.A., and the staff of the Washington Heights Community Service.

\section{References}

1. Cournos F, Empfield M, Horwath E, et al: HIV seroprevalence among admissions at two psychiatric hospitals. American Journal of Psychiatry 148:1225-1230, 1991

2. Volavka J, Convit A, Czobar P, et al: HIV seroprevalence and risk behaviors in psychiatric inpatients. Psychiatric Research 39:109-114, 1991

3. Sacks MH, Perry S, Graver R, et al: Selfreported HIV-related risk behaviors in acute psychiatric inpatients: a pilot study. Hospital and Community Psychiatry 41: 1253-1255, 1990

4. Kelly JA, Murphy DA, Bahr GR: AIDS/ HIV risk behavior among the chronic mentally ill. American Journal of Psychi- atry 149:886-889, 1992

5. Lyketsos G, Sakka P, Mailis A: The sexual adjustment of chronic schizophrenics: a preliminary study. British Journal of Psychiatry 143:376-382, 1983

6. Kay SR, Kalathara M, Meinzer AE: Diagnostic and behavioral characteristics of psychiatric patients who abuse substances. Hospital and Community Psychiatry 40:1062-1064, 1989

7. Spitzer RL, Williams JBW, Gibbon M: The Structured Clinical Interview for DSM-III-R (SCID). New York, New York State Psychiatric Institute, Biometrics Research, 1986

8. Williams JBW, Rabkin J, Remien R: Paraenteral Drug Use High-Risk Questionnaire. New York, New York State Psychiatric Institute, HIV Center, 1989

9. Meyer-Bahlburg HFL, Ehrhardt AA, Exner TM, et al: Sexual Risk Behavior Assessment Schedule, Psychiatric Inpatient Interview. New York, New York State Psychiatric Institute, HIV Center 1990

10. McKinnon K, Cournos F, Meyer-Bahlburg HFL, et al: Reliability of sexual risk behavior interviews with psychiatric patients. American Journal of Psychiatry, 150:972-974, 1993

\section{Letters}

Letters from readers are welcomed. They will be published at the discretion of the editor as space permits and will be subject to editing. They should be a maximum of 500 words with no more than five references and should be submitted in duplicate. Letters should be addressed to Jobn A. Talbott, M.D., Editor, HECP, APA, $1400 \mathrm{~K}$ Street, N.W., Washington, D.C. 20005.

\section{Helping Mentally Ill Mothers}

To the Editor: In the May issue Nicholson and associates (1) reported the findings of a survey of state mental health departments aimed at identifying state policies and programs focused on the needs of mentally ill mothers with preschool-age children. In Illinois, the task of funding and delivering programming for at-risk children has fallen by default to the Illinois Department of Children and Family Services. The Illinois Department of Mental Health refused to assume responsibility in 